\title{
Tannery Wastewater Treatment by Coagulation-Flocculation Technique Using Combination of Calcium Polysulfide and Ferrous Sulphate
}

\author{
Gedefaw Asmare ${ }^{1, *}$, Birhan Getachew², Tsegazeab Kassa², Wendifraw Abate ${ }^{2}$ \\ ${ }^{1}$ Faculty of Chemical and Food Engineering, Bahir Dar Institute of Technology- Bahir Dar University, Bahir Dar, Ethiopia \\ ${ }^{2}$ Department of Chemical Engineering, Debre Berhan University, Debre Berhan, Ethiopia
}

Email address:

gedepeng@gmail.com (G. Asmare)

${ }^{*}$ Corresponding author

To cite this article:

Gedefaw Asmare, Birhan Getachew, Tsegazeab Kassa, Wendifraw Abate. Tannery Wastewater Treatment by Coagulation-Flocculation Technique Using Combination of Calcium Polysulfide and Ferrous Sulphate. American Journal of Chemical Engineering.

Vol. 9, No. 4, 2021, pp. 79-83. doi: 10.11648/j.ajche.20210904.11

Received: June 3, 2021; Accepted: July 8, 2021; Published: July 15, 2021

\begin{abstract}
Effluents from the tannery industry have been a major source of environmental pollution. There is a need to evaluate the performance of wastewater treatment plant against regulatory standards. If in compliance found with standard, Employing appropriate treatment technique to meet the permissible discharge is important. In this reaction, performance evaluation of Tannery Wastewater and Treatment by coagulation technique of wastewater was investigated. Chemical oxygen demand (COD), Dissolved oxygen (DO), Total dissolved solids (TDS), Total suspended solids (TSS), chromium III and VI were the parameters selected to characterize the tannery waste water. From the characterization result of the factory effluent treatment plant it was found that; the factory effluent treatment plant meets the permissible discharge value in DO, Chromium III and VI. However, COD, TDS and TSS are far from the standards. Calcium polysulfide (CaSx) and ferrous sulphate $\left(\mathrm{Fe}(\mathrm{SO})_{4}\right)$ were the chemicals used for coagulation purpose. Treatment of $500 \mathrm{ml}$ original tannery waste with $400 \mathrm{mg}$ iron sulphate and variable calcium polysulfide concentrations (one, two and four $\mathrm{v} / \mathrm{v} \%$ ) was conducted and characterized. From characterization result, 400mg iron sulphate and $20 \mathrm{ml}$ of calcium polysulfide treatment yields water that full fill the standard of discharge limit except for COD. In addition, at this treatment the best closer value of COD $(1340 \mathrm{mg} / \mathrm{l})$ to the standard value $(250 \mathrm{mg} / \mathrm{l})$ was found.
\end{abstract}

Keywords: Waste Parameter, Effluent Treatment, Sedimentation, Calcium Polysulfide, Coagulation

\section{Introduction}

The leather industry is one of the major economic sectors, which the developing countries has given due consideration for the development. For instance, Ethiopia was able to export above US\$132million in the year 2017 from its leather and leather products industry [1]. Currently there are 30 tanneries, which are operational in this sector employing about 6000 workers. The current production capacity based on 15 tanneries is estimated at $6,000,000$ to 8,000000 kilograms of hides and 20,000, 000 to $25,000,000$ skins [2]. The hides are processed up to wet blues, crust and finished leather. The wet blues and crust hides are produced for export and the remaining low quality are finished for local market in the form of garments uppers and linings [3]. However, the industrial establishments for sustained economic development have been constrained ascribed to improper designed and operation in sustainable. In Ethiopia, the annual volume of liquid waste discharge from the 15 tanneries based on their annual production capacities is estimated to vary between 2,000,000 and 2,500,000 cubic meters [4]. Almost every tannery industry uses significant amounts of chemicals in the process of transforming animal hides into leather [5]. Usually the effluents from such tanning industries possess extremely high values (above the permissible standards of discharge) of Chemical Oxygen Demand (COD), Total Dissolved Solids (TDS), chromium ions, and Total Suspended Solids (TSS) [6]. Tannery waste water contains a complex mixture of both organic and inorganic pollutants, which brings serious environmental impact on water (with its 
high oxygen demand, discolouration and toxic chemical constituents, terrestrial and atmospheric systems [7]. For example, Nitrate loads from wastewater treatment and oxidative treatments affect heavily marine eutrophication (0.69 g N eq/ kg crust leather) [8].

Most of tanneries do not have treatment facilities and environmental management systems, as a result simply discharging their wastes into the environment. Thus, they are causing serious environmental and public health problems in particular in urban centers. It is obvious that the effect will further extend to rural areas as well. Besides, the loss of economic benefits that derived from this sector, cannot survive a growing challenge of environmentally sound competitive business unless appropriate environmental management system is introduced [9]. Chemicals used for tanning processes are the main sources of negative impacts. The tanning industry gives rise to two types of hazard involving chemicals. These are, firstly, those concerning particular chemicals used in the various tanning processes, and secondly, chemical substances produced as byproducts by the chemical reactions occurring when a hide undergoes the tanning process [10].

Even though the government forced the tanning industries to treat their wastes and meet the standard requirement before discharging to the environment, very small numbers of Ethiopian tanneries have used treatment plant which full fill the discharge standard of the nation. Therefore, evaluating the tannery WWTP against standard of discharge and proposing treatment method, which is less costly and with no side effects on the environment is timely and important. In this paper, the wastewater from Debre Birhan Tannery was characterized and treated with coagulant chemicals for sedimentation of water pollutants.

\section{Materials and Methods}

\subsection{Waste Water Characterization (WWTP Evaluation)}

In order to evaluate the WWTP performance, Influents and effluents wastewater samples were collected from WWTP of a local chrome-based tannery while it was working with its full capacity. Before getting to the treatment plant, the wastewater passes through some physical treatment/screening processes. The treatment plant uses alum and polyelectrolytes to remove pollutants using coagulationflocculation systems before discharging into the nearby river. The wastewater characterization was evaluated by Chemical Oxygen Demand (COD), Dissolved Oxygen (DO), Chromium ions, Total Dissolved Solids (TDS), Total Suspended Solids (TSS); because these are the common waste water pollution parameters $[11,12]$ and even difficult to minimize their values by preliminary treatment plants [13]. The two wastewater samples characterization was performed in Ethiopian Leather Industries Development Institute (ELIDI), Addis Ababa for these parameters and corresponding test methods (Table 1). Three replicates were conducted for each parameter and average value was taken as actual value.

Table 1. Water quality parameter tests and the corresponding test methods.

\begin{tabular}{lll}
\hline S. No & Type of test & Test method \\
\hline 1 & Chemical oxygen demand (COD) & APHA5220-COD B \\
2. & Dissolved oxygen (DO) & APHA4500- OG \\
3. & Total dissolved solids (TDS) & SLC 13 \\
4. & Total suspended solids (TSS) & APHA2540-D \\
5. & Chromium hexavalent (Cr $\left.{ }^{+6}\right)$ & SLC 22 \\
6. & Chromium trivalent $\left(\mathrm{Cr}^{+3}\right)$ & SLC208 \\
\hline
\end{tabular}

\subsection{Waste Water Treatment with Calcium Polysulphide}

Iron sulfate $(\mathrm{FeSO} 4)$ and calcium polysulfide $(\mathrm{CaSn})$ combination effect reduces leachability and toxicity of hexavalent chromium $(\mathrm{Cr}(\mathrm{VI}))$ in contaminated soil [14]. These coagulant chemicals combined effect also have a possibility of simultaneous removal of pollutants in waste water [15]. Effluent sample from the tannery before inflowing to the WWTP was taken for chemical treatment. Chemicals and materials used as inputs while conducting this treatment ware: Calcium poly sulfide solution $(\mathrm{Ca}(\mathrm{S}) \mathrm{n})(20 \%$, v/v), Iron (II) sulfate $\left(\mathrm{FeSO}_{4}\right)$ and calcium hydroxide $(\mathrm{CaOH})$, sulfuric acid $\left(\mathrm{H}_{2} \mathrm{SO}_{4}\right)$. All these analytical grades were procured from different chemical supply shops, Addis Ababa. Distilled water was used throughout the whole experiments. The treatment experiment was done at Debre Berhan University, Chemical Engineering Department Laboratory.

\subsection{Methods}

Waste water sample was poured in to three equal size measuring cylinders of $500 \mathrm{ml}$ for investigation of varying dose of calcium polysulfide [16]. The $\mathrm{PH}$ of these wastewater samples was adjusted to $12 \mathrm{PH}$ using calcium hydroxide or sulfuric acid. Constant Iron sulfate dose of $800 \mathrm{mg} / \mathrm{L}$ was added in to each of the three prepared samples followed by vagarous stirring for about 10 minutes [17]. Then calcium polysulfide dose of 1, 2 and $4 \% \mathrm{v} / \mathrm{v}$ of wastewater was added in to sample 1, sample 2 and sample 3 respectively. After 5 minutes stirring the samples were let to sediment for 12 hours [18]. The supernatants were taken for characterization of dissolved oxygen, chemical oxygen demand, chromium (III), chromium (VI), total suspended solids and total dissolved solids in Ethiopian Leather Industries Development Institute (ELIDI), Addis Ababa. All experiments were carried out at room temperature and were performed twice to ensure repeatability of the data. The settling rate of these three samples were also recorded.

\section{Results and Discussions}

\subsection{Characterization of Factory Waste Before and After Treatment with the WWTP Treatment Plant (WWTP)}

The tannery waste water characterizations are summarized in Table 2. The value of several parameters is higher than standards set by environmental protection authority for discharge. The waste characterization result is useful in order 
to analyze: (1) the waste load generated from the factory, (2) how much the current factory treatment plant treat its waste and (3) the effectiveness of the waste treatment (iron sulfate and calcium poly sulfide simultaneously) used in this research work. Characterization result of the local tannery wastewater is presented in Table 3 . The factory treatment plant minimizes the waste load generated at least by $15 \%$ and at most by $99.9 \%$ before discharge to the surrounding. In chromium treatment, the plant is effective and it meets the standard of discharge in chromium trivalent and very closer for chromium hexavalent. However, the organic wastes are too far from the discharge allowance.

Table 2. Wastewater characterization before and after treatment at Debre Berhan Tannery.

\begin{tabular}{llll}
\hline Parameter & $\begin{array}{l}\text { Waste water } \\
\text { before treatment } \\
\text { by WWTP }\end{array}$ & $\begin{array}{l}\text { Waste water } \\
\text { after treatment } \\
\text { by WWTP }\end{array}$ & $\begin{array}{l}\text { Standard } \\
\text { value [19] }\end{array}$ \\
\hline $\mathrm{DO}\left(\mathrm{mg} \mathrm{O}_{2} / \mathrm{L}\right)$ & 8.081 & 6.85 & 4.5 \\
$\mathrm{COD}(\mathrm{mg} \mathrm{O} / \mathrm{L})$ & 9670.6 & 4150 & 250 \\
$\mathrm{Cr}^{6+}(\mathrm{mg} / \mathrm{L})$ & 0.384 & 0.106 & 0.1 \\
$\mathrm{Cr}^{3+}(\mathrm{mg} / \mathrm{L})$ & 970.5 & $\mathrm{ND}$ & 2 \\
$\mathrm{TSS}(\mathrm{mg} / \mathrm{L})$ & 14084 & 968 & 600 \\
$\mathrm{TDS}(\mathrm{mg} / \mathrm{L})$ & 8000.3 & 4900 & 2100 \\
\hline
\end{tabular}

The WWTP eliminates all the generated trivalent chromium and has negligible discharge. However, the organic wastes are still in huge quantity in the discharge. This is because the factory uses flocculants and treating agents like polyelectrolyte, alum and lime but not as such effective. The treatment plant does not full fill the permissible discharge in TSS, TDS and COD parameters. COD, TSS and TDS parameters have 368, 2800, and $3900 \mathrm{mg} / \mathrm{L}$ differences respectively from the discharge standards.

\subsection{Characterization of the Tannery Waste After Treating with Calcium Polysulfide (CPS) and Iron Sulphate}

Characterization result of the above categories of wastes, which are generated waste from factory, waste from factory treatment plant and waste after treatment with iron sulfate and calcium poly sulfide are significantly different and it is reasonable. This is an indication of treatment capacity for each treatment method. Combination of calcium polysulfide and iron sulfate as a wastewater treatment minimizes the generated waste from the factory by more than $85 \%$ in all parameters of waste.

Treating the tannery waste with iron sulfate and calcium polysulfide shows appreciable minimization of the generated waste load from the factory. The treated waste meets the discharge standard for waste parameters discussed so far except COD.

Table 3. Characterization result of wastewater after treating with calcium poly sulphide at different concentration levels.

\begin{tabular}{llll}
\hline \multirow{2}{*}{ Parameter } & \multicolumn{3}{l}{ Calcium poly sulphide concentration } \\
\cline { 2 - 4 } & $\mathbf{1 \%}(\mathbf{V} / \mathbf{V})$ & $\mathbf{2 \%}(\mathbf{V} / \mathbf{V})$ & $\mathbf{4 \%}(\mathbf{V} / \mathbf{V})$ \\
\hline $\mathrm{DO}\left(\mathrm{mg} \mathrm{O}_{2} / \mathrm{L}\right)$ & 4.8 & 4.4 & 4.6 \\
$\mathrm{COD}\left(\mathrm{mg} \mathrm{O}_{2} / \mathrm{L}\right)$ & 2490 & 1870.4 & 1340.7 \\
$\mathrm{Cr}^{+6}(\mathrm{mg} / \mathrm{L})$ & 0.1 & 0.05 & 0.02 \\
$\mathrm{Cr}^{+3}(\mathrm{mg} / \mathrm{L})$ & $\mathrm{ND}$ & $\mathrm{ND}$ & $\mathrm{ND}$ \\
$\mathrm{TSS}(\mathrm{mg} / \mathrm{L})$ & 730 & 0.7 & 0.2 \\
$\mathrm{TDS}(\mathrm{mg} / \mathrm{L})$ & 2200 & 93.3 & 86.2 \\
\hline
\end{tabular}

This treatment technique involves in only a single tank, which means Removal of heavy metals, and settlement of organic wastes occurs simultaneous. This is due to the multipurpose of calcium polysulfide. Calcium polysulfide with higher concentration $(4 \% \mathrm{~V} / \mathrm{V})$ gives the best discharge waste parameter. Therefore, this is the optimum dosing for the given waste load treatment. The only parameter that does not meet the discharge limit is COD. By this combined effect of iron sulphate and calcium polysulfide, $86.13 \%$ removal of COD is achieved, which is comparable to removal $95.95 \%$ by electrocoagulation [15] and $95.4 \%$ removal by combined process of biological, chemical coagulation and oxidation [20]. However, there is a significant minimization of load. The comparison of the original, standard, ETP and 1, 2, 4 $\mathrm{V} / \mathrm{V} \%$ CPS treatment is shown in the figure below.

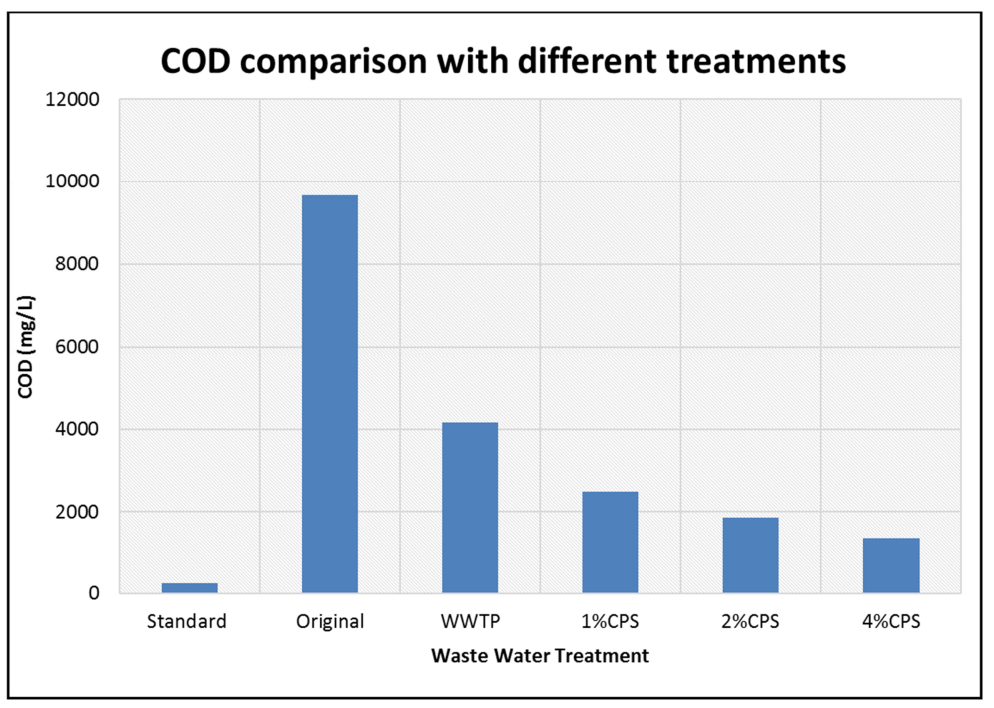

Figure 1. Comparison of the COD concentration in different treatment techniques. 
As it can be seen from the above figure, the treatment technique which yields the possible closer value to the standard is treatment of waste with four $\mathrm{V} / \mathrm{V} \%$ of calcium poly sulfide. An average settling rate data for sedimentation process is tabulated as below.

Table 4. Height of clear liquid interface as the function of settling time.

\begin{tabular}{|c|c|c|c|c|c|c|c|c|c|c|c|c|c|}
\hline Settling time (hr.) & $\mathbf{0}$ & 1 & 2 & 3 & 4 & 5 & 6 & 7 & 8 & 9 & 10 & 11 & 12 \\
\hline Height of clear liquid interface $(\mathrm{mm})$ & 500 & 350 & 250 & 220 & 200 & 190 & 184 & 180 & 178 & 177 & 176 & 175 & 175 \\
\hline
\end{tabular}

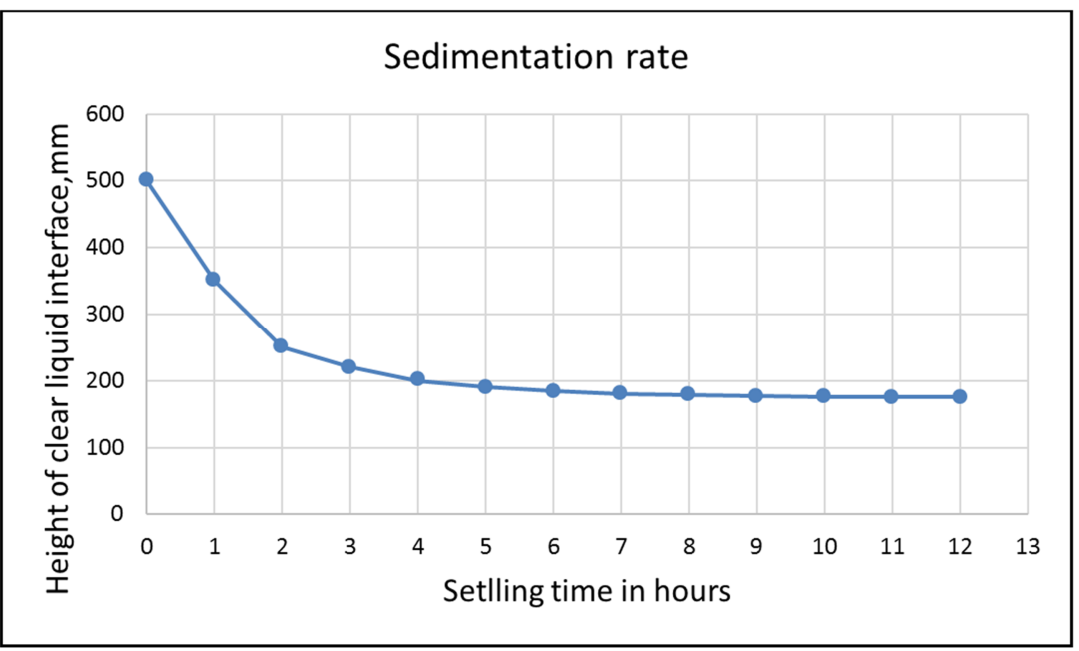

Figure 2. Bach settling of a tannery waste when treated with CPS.

The settling rate is very high for the first 2 hours of sedimentation. After that, there is low sedimentation for the chemical treatment process. There fore increasing the settling time beyond 12 hours is time taking only.

\section{Conclusions}

In conclusion, it has been found that, local Tannery factory's effluent treatment plant (ETP) is effective in trivalent chromium removal. The ETP also minimizes other wastes at least by $50 \%$ of the waste generated. When the generated waste of the factory was treated with $4 \% \mathrm{v} / \mathrm{v}$ of calcium polysulfide and $800 \mathrm{mg} / 1$ of iron sulfate, at least $85 \%$ of the generated waste was removed. All the selected waste parameters except COD, meets the standards of discharge when this treatment method is applied. To achieve the COD level biological or secondary treatment required. The different pollutants present in the tannery waste can be separated using small amount of calcium polysulfide, iron sulfate and lime if necessary in a single tank the so-called sedimentor or clarifier. The treatment efficiency of wastewater can be affected by different factors like $\mathrm{pH}$, temperature, concentration of iron sulfate or effect of any other flocculants. Therefore, the effect of several factors on tannery waste treatment can be studied in future.

\section{Acknowledgements}

First and foremost, Glory to the almighty GOD for being with us in all our endeavors. We are thankful for Debre Berhan University, for the financial support, Debre Berhan
Tannery, for their collaboration throughout the research work and Ethiopian leather industries development institute for cooperativeness, during sample analysis.

\section{Conflict of Interest}

The authors declare that there is no conflict of interest regarding the publication of this paper.

\section{References}

[1] J. Grumiller and W. Raza, "The Ethiopian Leather and Leather Products Sector : An Assessment of Export Potentials to Europe and Austria," Res. Rep., no. 11, 2019.

[2] UNIDO, "United Nations International Development Organization Annual Report 2012,” 2013.

[3] Unido, "OCCASION This publication has been made available to the public on the occasion of the 50," p. 153, 2007.

[4] Euc, "Integrated pollution prevention and control: draft reference document on best available techniques in the tanning of hides and skins," no. February, pp. 1-241, 2009.

[5] H. Dargo and A. Ayalew, "of Emerging Trends in Science and Technology Tannery Waste Water Treatment: A Review," 2014.

[6] M. Chowdhury and M. G. Mostafa, "Characterization of the Effluents from Leather Processing Industries,” pp. 173-187, 2015, doi: 10.1007/s40710-015-0065-7.

[7] M. Mwinyihija, Ecotoxicological Diagnosis in the Tanning Industry. 2010. 
[8] A. L. Tasca and M. Puccini, "Leather tanning: Life cycle assessment of retanning, fatliquoring and dyeing," J. Clean. Prod., vol. 226, pp. 720-729, 2019, doi: 10.1016/j.jclepro.2019.03.335.

[9] abdulhamid B. Abebe Zeleke, "Tannery Wastewater Management problems in Ethiopia: The case of Batu tannery," 2011.

[10] J. Ludvik, "The scope for decreasing pollution load," no. August, pp. 1-36, 2000.

[11] R. Naresh, B. Gaurav, S. Sikandar, I. M. Devendra, and K. Patel, "Characterization and Identification of Recalcitrant Organic Pollutants (ROPs) in Tannery Wastewater and Its Phytotoxicity Evaluation for Environmental Safety," Arch. Environ. Contam. Toxicol., vol. 75, no. 2, pp. 259-272, 2018, doi: 10.1007/s00244-017-0490-x.

[12] S. Aber, D. Salari, and M. R. Parsa, "Employing the Taguchi method to obtain the optimum conditions of coagulation flocculation process in tannery wastewater treatment," Chem. Eng. J., vol. 162, no. 1, pp. 127-134, 2010, doi: 10.1016/j.cej.2010.05.012.

[13] A. Yadav et al., "Chemosphere Phytotoxicity, cytotoxicity and genotoxicity evaluation of organic and inorganic pollutants rich tannery wastewater from a Common Ef fl uent Treatment Plant (CETP) in Unnao district, India using Vigna radiata and Allium cepa," Chemosphere, vol. 224, pp. 324-332, 2019, doi: 10.1016/j.chemosphere.2019.02.124.

[14] T. Zhang, Q. Xue, and M. Wei, “applied sciences Leachability and Stability of Hexavalent-Chromium-Contaminated Soil Stabilized by Ferrous Sulfate and Calcium Polysulfide," no. 1, pp. 1-11, 2018, doi: 10.3390/app8091431.
[15] K. Cheballah, A. Sahmoune, K. Messaoudi, and N. Drouiche, "Chemical Engineering and Processing: Process Intensi fi cation Simultaneous removal of hexavalent chromium and COD from industrial wastewater by bipolar electrocoagulation," Chem. Eng. Process. Process Intensif., vol. 96, pp. 94-99, 2015, doi: 10.1016/j.cep.2015.08.007.

[16] S. M. Dahlawi and S. Siddiqui, "Calcium polysulphide, its applications and emerging risk of environmental pollution-a review article," Environ. Sci. Pollut. Res., vol. 24, no. 1, pp. 92-102, 2017, doi: 10.1007/s11356-016-7842-3.

[17] T. Verma, P. W. Ramteke, and S. K. Garg, "Quality assessment of treated tannery wastewater with special emphasis on pathogenic E. coli detection through serotyping," Environ. Monit. Assess., vol. 145, no. 1-3, pp. 243-249, 2008, doi: 10.1007/s10661-007-0033-4.

[18] T. Mpouras, N. Papassiopi, K. Lagkouvardos, C. Mystrioti, and D. Dermatas, "Evaluation of Calcium Polysulfide as a Reducing Agent for the Restoration of a Cr(VI)-Contaminated Aquifer," Bull. Environ. Contam. Toxicol., no. Vi, 2020, doi: 10.1007/s00128-020-02890-1.

[19] EPA, "Environmental Impact Assessment Guideline Document Environmental Protection Authority. Final Draft," no. May, 2000.

[20] S. Kim, C. Park, T. H. Kim, J. Lee, and S. W. Kim, "COD reduction and decolorization of textile effluent using a combined process," J. Biosci. Bioeng., vol. 95, no. 1, pp. 102105, 2003, doi: 10.1263/jbb.95.102. 